\title{
Aesthetic Dentistry, How You Say and How You See: A 500-People Survey on Digital Preview and Color Perception
}

This article was published in the following Dove Press journal: Clinical, Cosmetic and Investigational Dentistry

\author{
Francesca Zotti (D) \\ Davide Pappalardo (i) \\ Giorgia Capocasale (ID \\ Andrea Sboarina \\ Dario Bertossi (D) \\ Massimo Albanese (D) \\ Department of Surgical Sciences, \\ Paediatrics and Gynecology, University of \\ Verona, Verona, Italy
}

Correspondence: Francesca Zotti Department of Surgical Sciences, Paediatrics and Gynecology, University of Verona, P.le L.A. Scuro, 10, Verona $37 \mid 34$, Italy

$\mathrm{Tel} / \mathrm{Fax}+390458126938$

Email francesca.zotti@univr.it
Purpose: Digital technologies have improved ways to perform aesthetic dentistry in the last few years. The aims of this survey were to investigate the most preferred way to preview the result of an aesthetic dental rehabilitation among a population of dental professionals and laypeople and to compare aesthetic standards of the general population and dentists in terms of the color of teeth for aesthetic dental rehabilitations.

Patients and Methods: A questionnaire was sent to the subjects (dentists and laypeople) during a 1-year period and, together with their demographic data, different ways to preview the result of an aesthetic rehabilitation were submitted, such as digital smile design, dental wax-up and oral explanation. Furthermore, an additional section of the questionnaire investigated the most suitable color for an aesthetic rehabilitation based on the colors of the VITA Scale. Results were statistically analyzed (with Chi-square of independence and MannWhitney $U$-test) highlighting differences of answers based on age groups, educational attainment, gender, and belonging or not to the dental field.

Results: Findings showed that digital smile design (digital preview) is a high-appreciated method for previewing and communicating with patients both by dental professionals and laypeople. Furthermore, lighter colors were found to be more valued by laypeople and significant differences were highlighted between the two populations assessed.

Conclusion: It seems to be viable to use digital preview for dentists and laypeople to improve previewing and communicating ways. It might be advisable to better motivate patients in recognizing aesthetical features and to raise their awareness in preferring more mimetic aesthetic results. Great opportunities are opened up by digital smile design in teaching, learning, and routine practice.

Keywords: digital smile, patient communication, aesthetic colours, aesthetical idea, digital dentistry

\section{Introduction}

An important part of dental aesthetic rehabilitation is the preview of the final result. This issue has a twofold effect both for patients and for all dental team actors. ${ }^{1}$

In searching to perform aesthetic rehabilitations, a method to plan and to show the patient the final result of the project is desirable.

Past literature and dental practice offered different modalities of planning and preview including intraoral mock-up and wax-up, still used in clinical routine. ${ }^{2}$ Nowadays, a new way of planning and communicating, represented by Digital Smile Design (DSD), was introduced in dental practice. 
DSD is a multi-use tool to improve diagnosis and design of aesthetic dental rehabilitations, allowing a suitable aesthetic analysis of baseline patient's conditions and the resolution of diagnostic critical points. ${ }^{3}$

This instrument makes possible effective communication from the dentist to the patient and dental technicians, minimizing errors and misunderstandings that can affect the final result. All these advantages in the diagnostic and pre-operative phases improve and facilitate the global aesthetic treatment. ${ }^{4-6}$ Recent literature has offered important and strong findings about the feasibility of using digital tools in dentistry, especially in the planning phases of great prosthetic rehabilitations. $^{7-10}$

Digital Smile Design works on photographs of patient's smile and face through a software allowing modification of shape, color, and position of teeth and soft tissues. ${ }^{11}$

It can be applied in different fields of aesthetic dentistry such as for reconstructions or modifications of anterior dentition, as a planning tool for prosthetic workflow, and orthodontics and periodontics treatments. ${ }^{1,12}$

The most used software to perform DSD are, at the moment, Keynote (iWork, Apple, Cupertino, CA, USA) and PowerPoint (Microsoft Office, Microsoft, Redmond, WA, USA), free software enabling a large number of modifications on digital photos. Also, Adobe Photoshop (Adobe Inc, San Jose, CA, USA) is employed thanks to the large number of tools at disposal, however, licence cost may be considered a defect as well as the learning curve needed to use it. ${ }^{13}$ Other software used in creating DSD are made by dental companies specifically for dentist's use, however they are expensive and with less functionality than the above-mentioned types. ${ }^{13}$

Nonetheless, traditional techniques including wax-up and intraoral mock-up, procedures requiring certain compliance of patients, chairside costs and material consuming, are still used.

With this in mind, the aims of this survey were: 1) to evaluate the most preferred method of previewing results of aesthetic dental rehabilitation among the population; and 2) to compare the aesthetic standards of the general population and dentists in terms of the color of teeth for aesthetic dental rehabilitations.

\section{Materials and Methods}

A survey was carried out between March 2019 and March 2020 among a random sample of volunteers in Italy. No incentive was offered to participants.
An anonymous web-based questionnaire in the Italian language was shared with an Italian-speaking sample by means of e-mail, WhatsApp ${ }^{\mathrm{TM}}$ and Telegram Messenger chat room and Facebook. It was created by Google Forms (Alphabet Co., Mountain View, CA, USA), the survey was electronically answered and the answers were linked to the author's Google Account. To ensure data security, results were not made public. It required approximately $10 \mathrm{~min}-$ utes to complete. It was completely anonymous and no sensitive data were asked.

The questionnaire was sent to students of the Dental School of Verona and to dental practitioners asking them to share it with patients and to the general population by URL sharing, by building on the knowledge of all authors and colleagues.

The study protocol and the questionnaire were also approved by the review board of the Dental School of Verona (University of Verona, Italy). Ethical Committee approval was not asked for because the respondents and their personal data were protected by anonymity. Not even the person who analyzed the data could link information to a specific person, furthermore, people could not be recognized by the answers given.

The validity of a questionnaire is determined by analyzing whether the questionnaire measures what it is intended to measure. The content validity was assessed by a panel of Researchers of the Dental School of Verona (Review Board) as done in a previous work. ${ }^{14,15}$

All questions were clear and unambiguous: a pilot test of the questionnaire was performed among a random sample of 10 patients referred to our department (on a volunteer basis) to ensure practicability, validity, and interpretation of answers. Then, the questions were revised considering the comments obtained before sharing the link of the web-based questionnaire to the study sample.

All data were recorded in a database and processed by only one operator (PD).

The questionnaire consisted of three main sections: 1) Demographic data; 2) Favorite "Previsualization Method"; 3) Aesthetic Perception data. The questionnaire was created as follows:

1. Demographic data:

a. Gender: possible answers male and female.

b. Age: 4 options given: 15-25 years old, 25-35 years old, 35-50 years old and $>50$ years old. 
c. Education attainment: choices reporting Italian school system (graduation, high school, junior high school, elementary education).

d. Belonging to the dental field or not (general population).

2. Favorite "Preview Method": the question aimed to investigate the favorite method to preview the final result in dental aesthetic rehabilitation; options were: Digital Smile Design (DSD); dental wax-up; oral explanation of dentist; other. Each option was accompanied by an image and/or a small description. (Figure 1).
3. Aesthetic Perception data: evaluation of the most suitable color for an aesthetic rehabilitation based on the colors of the VITA Scale (VITA Zahnfabrik, Bad Säckingen, Germany). Respondents had to assign to each color (A1, A2, A3, A3.5 and A4) an aesthetic rate: excellent; very aesthetic; aesthetic; not very aesthetic; bad. Digital photographs of differently colored templates were provided to the respondents (Figure 2).

Respondents were divided into two groups: general population and dentists. The dentists' category also comprised

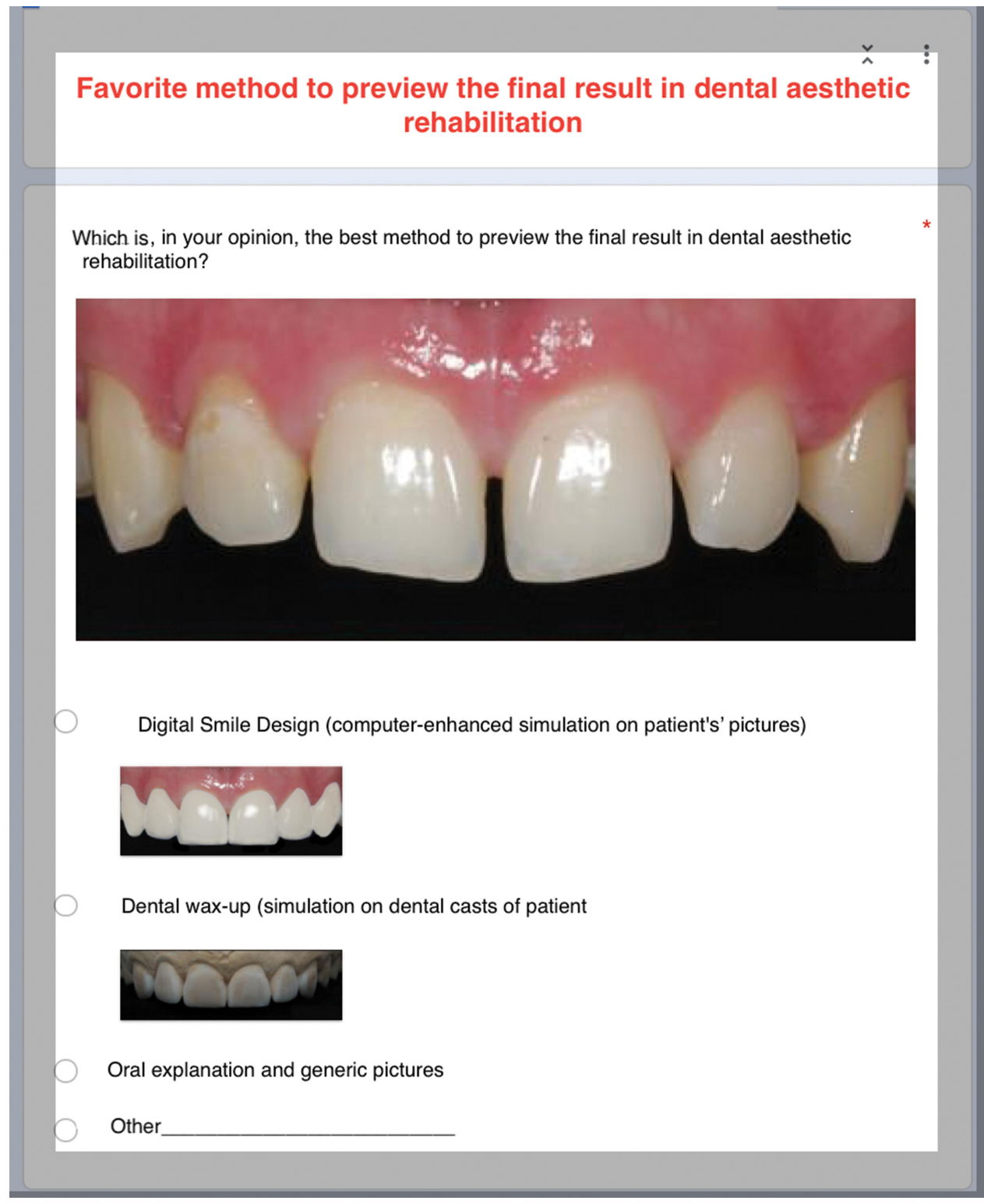

Figure I Options of questionnaire to point the favorite method of preview. 
Which is, in your opinion, the most suitable colour for an aesthetic rehabilitation
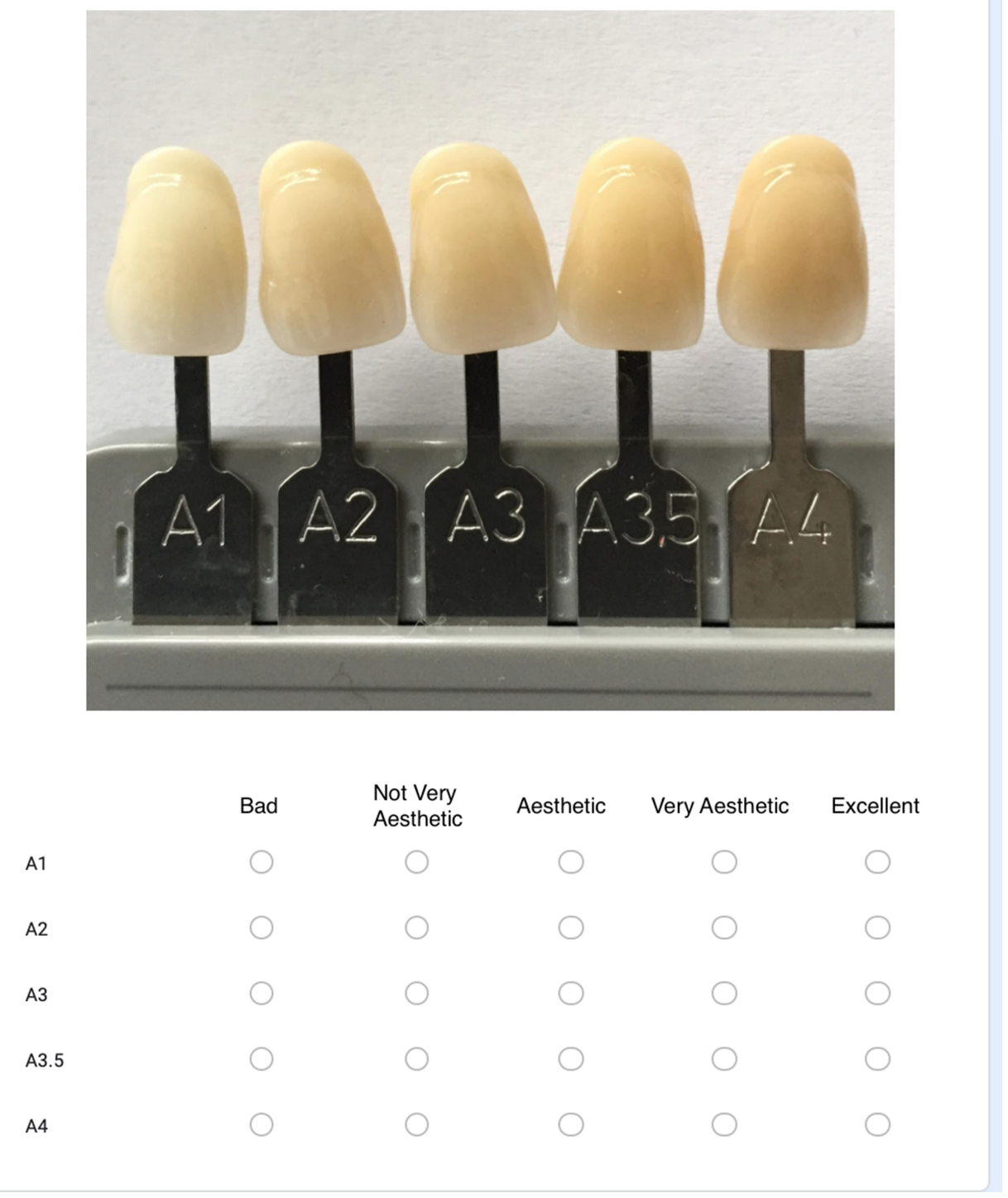

Figure 2 Colored templates for choosing the aesthetical rate.

dental students to distinguish between people with knowledge in the dental field and those still learning in this field.

\section{Statistical Analysis}

Data were statistically analyzed as follows:

-Descriptive statistics were performed to assess the distribution of different answers among the population and to analyze the demographic data of people surveyed.

-Chi-square of independence test with adjusted residuals calculation was run to analyze the relationship between the favorite method of preview and the following variables: educational attainment, belonging to dental field or not (dentists or general population), gender and age group. The tests were considered statically significant for $P \leq 0.05$. The post hoc analysis with adjusted standardized residuals (ASR) calculation was run. The ASR with an absolute value greater than $2.58(P \leq 0.01)$ were considered of interest. ${ }^{16}$

-Regarding different colours of rehabilitations (A1, A2, A3, A3,5, A4), a Mann-Whitney $U$-test was used to determine differences in aesthetic perception (measured on a five-point scale from 5="excellent" to $1=$ "bad") between dentists and the general population. The test was considered statistically significant for $P \leq 0.05$. 
Statistical analysis was performed using Statistical Package for Social Sciences Version 20.0 (IBM Corp., Armonk, NY, USA) and setting the significance level at 0.05 .

\section{Results}

Over a period of 4 months, a total of 500 participants completed the web-based questionnaire.

\section{Demographic Data}

Demographic details of the study population are illustrated in Table 1.

The sample comprised $54.6 \%$ of females and $45.4 \%$ males. Age distribution comprised $40 \%$ in the $15-25$ years old age group, $26.8 \%$ in the $25-35$ years old age group, $17.8 \%$ in the $35-50$ years old age group and $15.4 \%$ in the $>50$ years old age group.

Half $(49.2 \%)$ of the participants declared they had a high school diploma, $43.6 \%$ had graduated, $6.4 \%$ had a junior school diploma, and $0.2 \%$ an elementary education; moreover, $36.8 \%$ of respondents belonged to the dental field (dentists) and $63.2 \%$ were represented by the general population.

\section{Favorite "Preview Method"}

The favorite method to preview the final result in dental aesthetic rehabilitation resulted in $68.8 \% \mathrm{DSD}, 22.2 \%$ dental wax-up and $7.2 \%$ oral explanation of dentist; $1.4 \%$ of the

Table I Demographic Distribution of Sample

\begin{tabular}{|l|l|l|}
\hline & & N \\
\hline Gender & M & 227 \\
& F & 273 \\
& Total & $\mathbf{5 0 0}$ \\
\hline Age Group & $15-25$ years & 200 \\
& $26-35$ years & 134 \\
& $36-50$ years & 89 \\
& More than 50 years & 77 \\
& Total & $\mathbf{5 0 0}$ \\
\hline Status & Dentists & 184 \\
& Laypeople & 316 \\
& Total & $\mathbf{5 0 0}$ \\
\hline Educational Attainment & Elementary education & 1 \\
& Junior high school & 32 \\
& High school & 249 \\
& Degree & 218 \\
& Total & $\mathbf{5 0 0}$ \\
\hline
\end{tabular}

participants pointed out other methods (eg, Direct intra-oral mock-up or joint dental wax-up and DDS).

To deeply analyze the relationship between the favorite preview method and the demographic data, some subject groups were not included in the analysis because they did not meet the conditions of validity of the Chi Square test. Specifically, the group of respondents that pointed out "other" as favorite preview method (7 participants) was excluded from all assessments. Furthermore, only one respondent reported to have only an elementary education level (and chose "oral explanation" as the favorite preview method), therefore, he was not included in the analysis related to the educational attainment.

A significant relationship was found between the preview method and educational attainment (Chi-square $=12.07 ; P=0.017)$. In particular, this analysis showed only one ASR of interest with greater observed frequency than that expected for a person with junior high school education level who optioned for oral explanation (observed frequency $=6 ; \mathrm{ASR}=2.65$ ).

A highly significant relationship was found between the preview method and the status of people (belonging or not to the dental field) (Chi-square $=33.48 ; P<0.00001$ ). All the preview methods showed a significant contribution to this relationship. The greater values of ASR were observed for dental wax and DSD options. In particular, the observed frequency was greater than that expected for the DSD in the laypeople group (observed frequency $=236$; $\mathrm{ASR}=3.31$ ) and for the dental wax in the dentist group (observed frequency $=65$; ASR $=5.40$ ). A smaller contribution to the relationship was observed regarding the oral explanation where the observed frequency was lower than that expected for the dentist group (observed frequency $=5 ; \mathrm{ASR}=-2.88$ ).

Likewise, a clear relationship was observed between the preview method chosen and gender (Chi-square $=8.49$; $P=0.014$ ). It was due to choices of dental wax and DSD as favorite preview methods. In particular, the observed frequency for DSD as favorite preview method was greater than that expected in women (observed frequency $=203$; $\mathrm{ASR}=2.74$ ), whereas the observed frequency for dental wax as the favorite preview method was greater than that expected in men (observed frequency $=64 ; \mathrm{ASR}=2.83$ ).

A significant relationship was found between the preview method and age (Chi-square $=14.52 ; P=0.024$ ). Specifically, this analysis showed only one ASR greater than 2.58 resulted from respondents older than 50 years that optioned oral explanation as the favorite method (observed frequency=13; $\mathrm{ASR}=3.52$ ). 
Table 2 Chi-Square of Independence Analysis

\begin{tabular}{|l|l|}
\hline & Kind of Preview \\
\hline Gender & $* * P=0.014$ \\
Age groups & $* * P=0.024$ \\
Status & $* * P=0.00001$ \\
Educational attainment & $* * P=0.017$ \\
\hline
\end{tabular}

Note: **Highly statistically significant.

Table 2 and Figures 3-6 synthesize the descriptive and statistical analyses, about the favorite method of preview.

\section{Aesthetic Perception Data}

A descriptive analysis of answers is reported in Figures 7 and 8 .

Aesthetic perception of the colors A4, A3.5, A3 and A2 was found to be statistically different between the two groups (dentists and general population) with higher values in the dentist group (Table 3, Figure 9).

Conversely, the aesthetic perception of the colour A1 was statistically significantly higher in the general population group (Table 3, Figure 10).

Figures 7 and 8 and Table 3 synthesize the descriptive and statistical analysis, respectively.

\section{Discussion}

This cross-sectional study aimed to evaluate the most preferred method of previewing results of aesthetic dental rehabilitation among the population and to compare the aesthetic standard of lay people and dentists in terms of the color of teeth for aesthetic dental rehabilitations.

In this perspective, authors chose to group in the "dentists' group" both answers by dental practitioners and those from dental students to better highlight differences with the general population. We assumed that dental students could have more knowledge compared to the general population and, because of this, their answers might have been more similar to those who have already graduated in dentistry.

Nowadays aesthetic restorative dentistry has had a great booster by technology and dental material improvements. Thanks to these opportunities, the aesthetic goal of more mimic and natural results can be achieved more easily; dentists could reach high-performance results employing easy-to-use materials, at chair-side and in a satisfying way for patients. ${ }^{17}$

With this in mind, this survey aimed to evaluate the most suitable method to communicate and show the preview of results and, even more, to understand where the

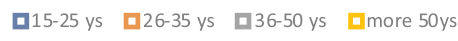

160

140

120

100

80

60
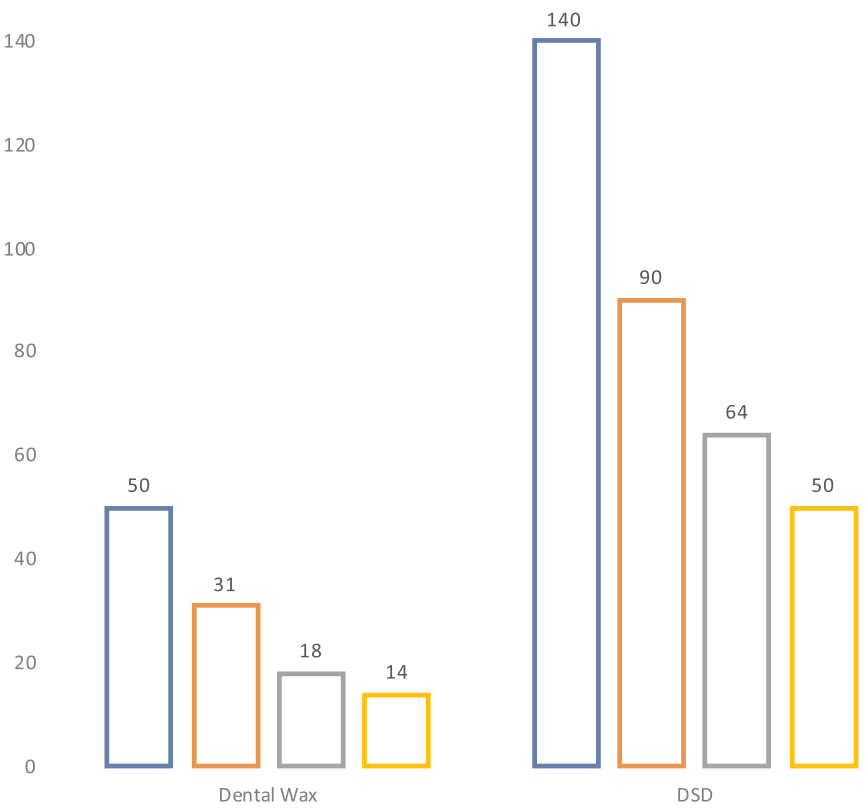

DSD

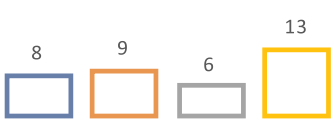

Oral Explaination

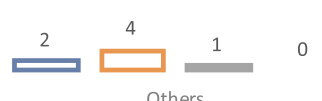

Others

Figure 3 Preferences of preview method based on age groups. 

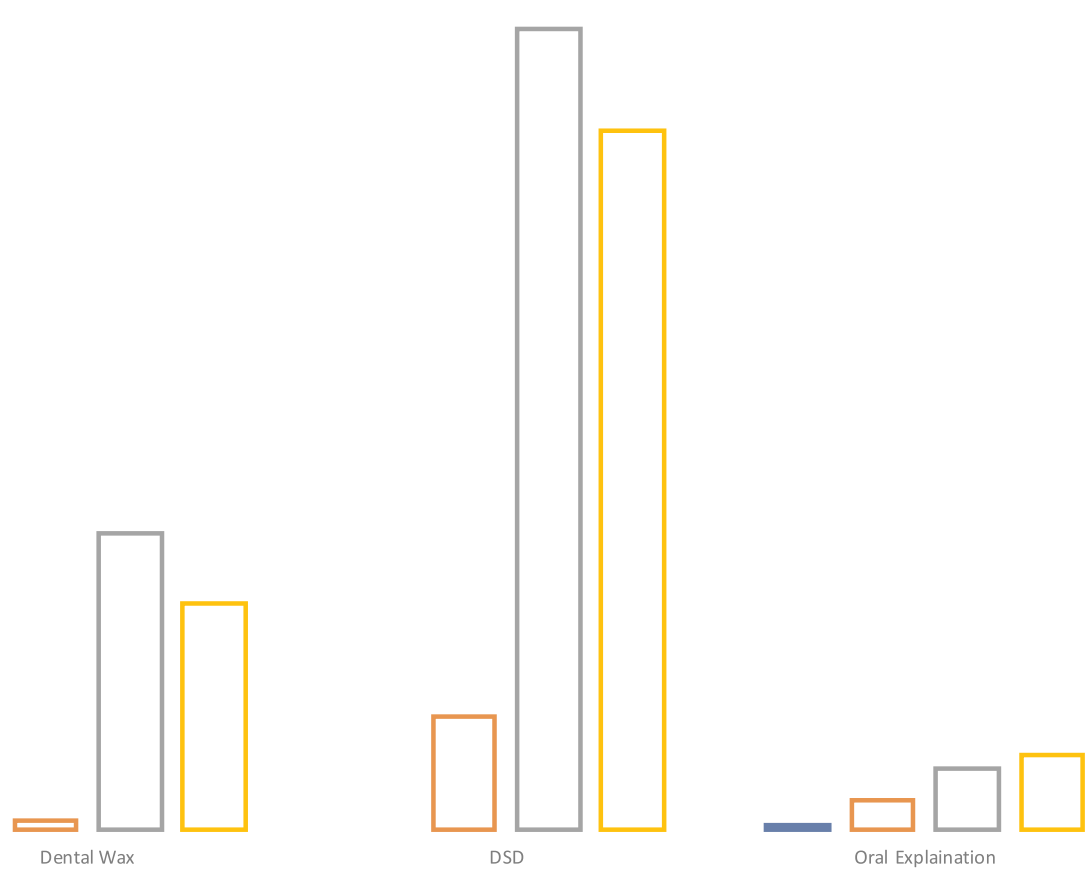

Figure 4 Preferences of preview method based on educational attainment.

Dentists DLaypeople

250

200

150

100
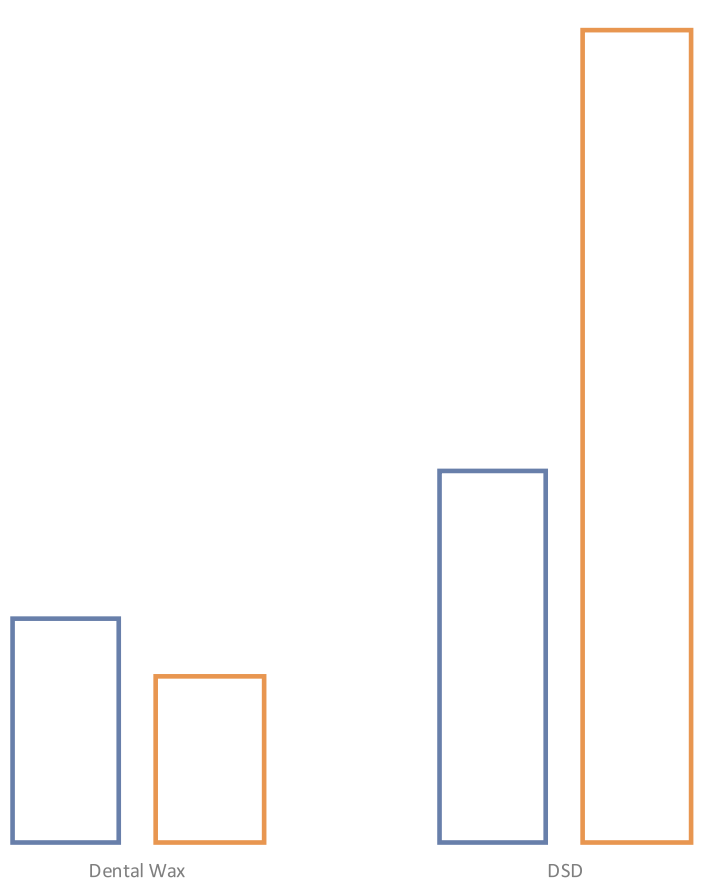

DSD

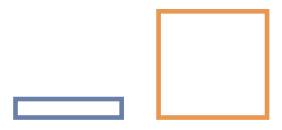

Oral Explaination

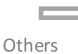

Dental Wax

Figure 5 Preferences of preview method based on status of people. 
DMale DFemale

250

200

150

100

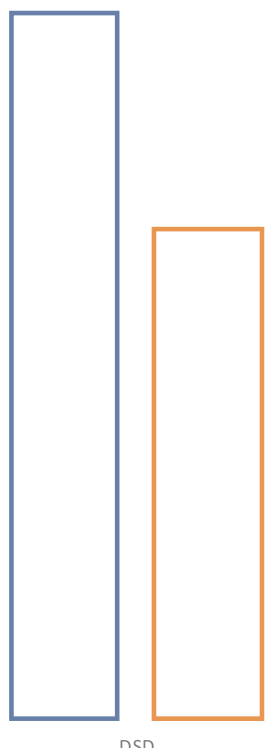

DSD
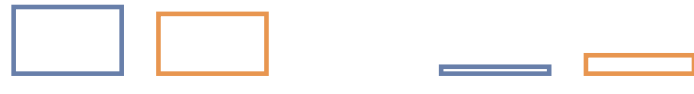

Dental Wax

Oral Explaination

Others

Figure 6 Preferences of preview method based on gender.

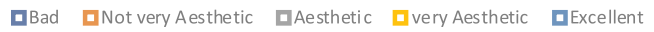

$60,00 \%$

$50,00 \%$

$40,00 \%$

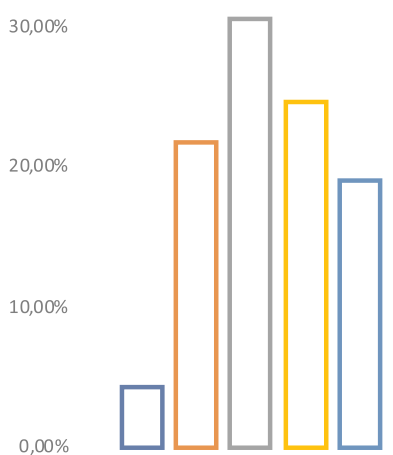

Colour A1

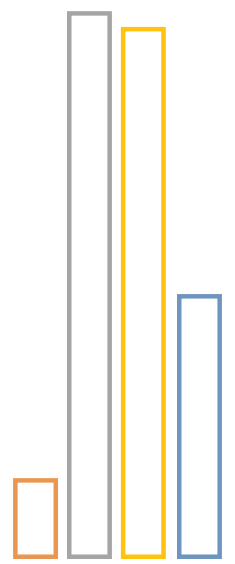

Colour A2

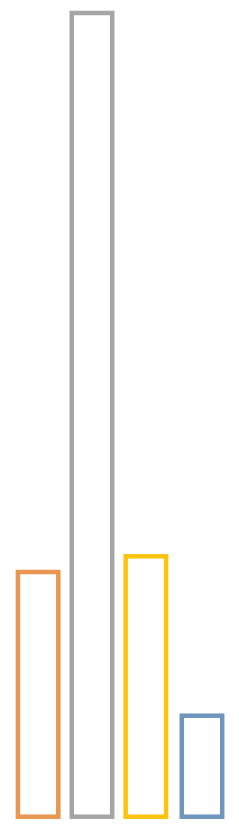

Colour A3

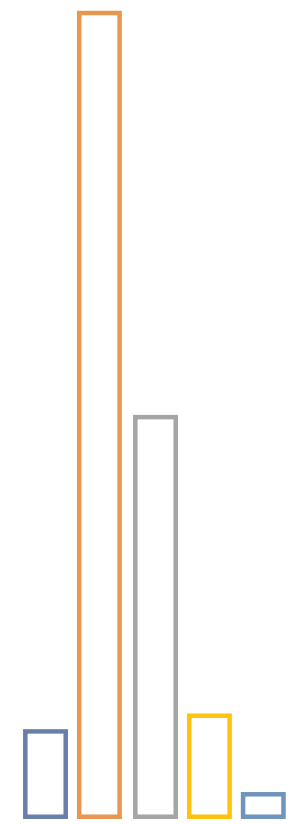

Colour A3,5

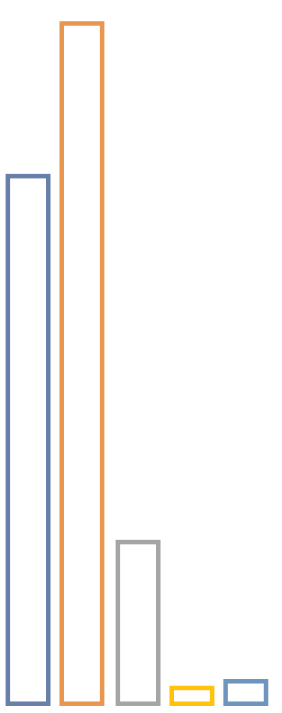

Colour A4

Figure 7 Graphical representation of answers from dentists about aesthetic perception of colors. 

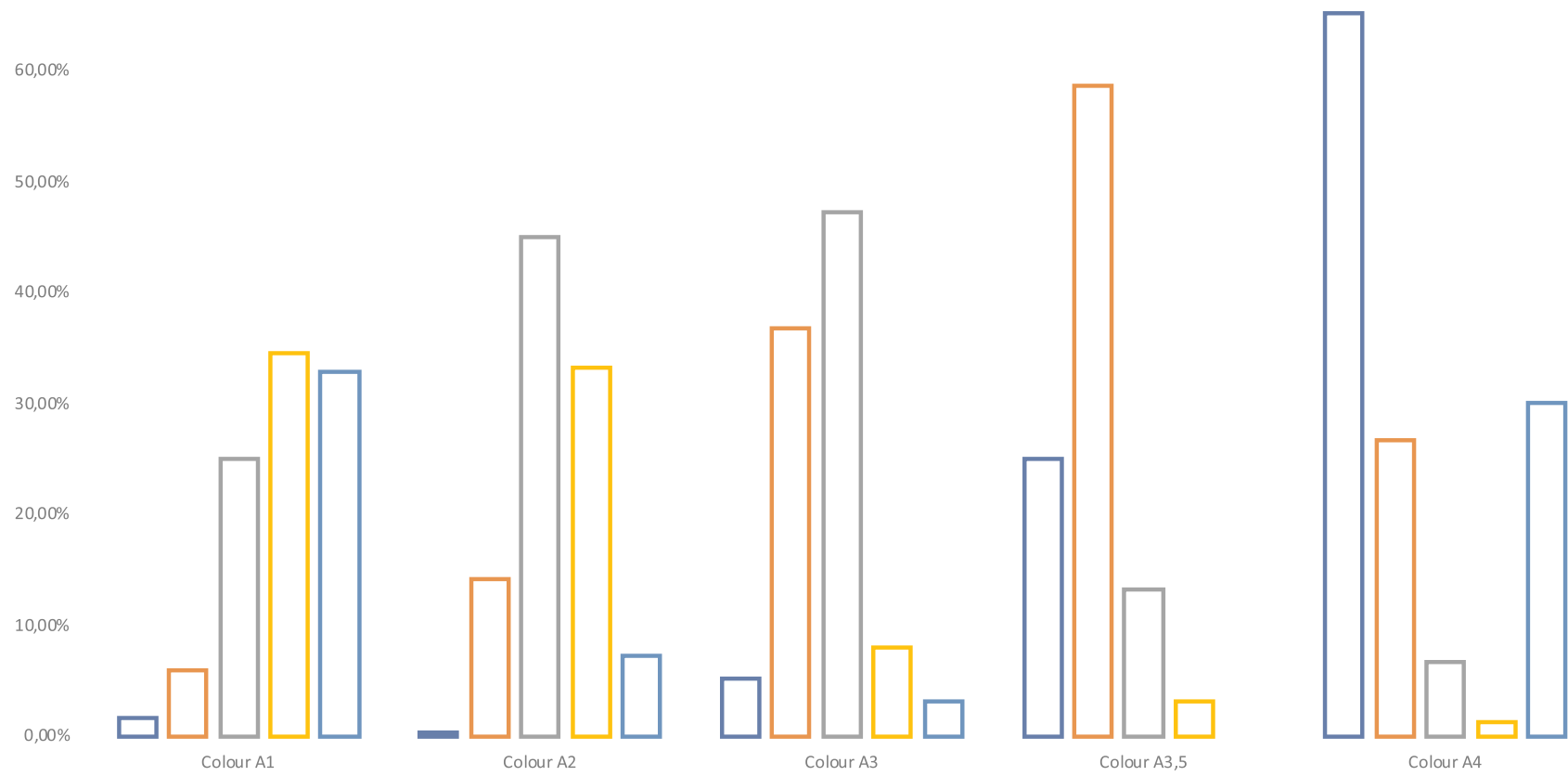

Figure 8 Graphical representation of answers from laypeople about aesthetic perception of colors.

aesthetical perception of colors is located. This issue is important because often the aesthetic ideal of dentists does not match the aesthetical ideal of patients who would desire to have teeth "more and more white and really straight" $" 18$ at the expense of naturalness.

Furthermore, the market launch of feasibility to digitally and more realistically preview the final results opened an interesting scenario about the preferences of patients and dentists.

Table 3 Mann-Whitney Test Analysis

\begin{tabular}{|l|l|l|l|l|l|}
\hline Color & Status & $\begin{array}{l}\text { Mean } \\
\text { Rank }\end{array}$ & $\mathbf{U}$ & $\mathbf{z}$ & P-value \\
\hline A1 & $\begin{array}{l}\text { Laypeople } \\
\text { Dentists }\end{array}$ & $\begin{array}{l}277.68 \\
203.82\end{array}$ & $20,483.5$ & -5.722 & $* *<0.000$ I \\
\hline A2 & $\begin{array}{l}\text { Laypeople } \\
\text { Dentists }\end{array}$ & $\begin{array}{l}230.19 \\
285.38\end{array}$ & $35,489,5$ & 4.396 & $* *<0.000$ I \\
\hline A3 & $\begin{array}{l}\text { Laypeople } \\
\text { Dentists }\end{array}$ & $\begin{array}{l}222.02 \\
299.42\end{array}$ & $38,072.5$ & 6.298 & $* *<0.000$ I \\
\hline A3.5 & $\begin{array}{l}\text { Laypeople } \\
\text { Dentists }\end{array}$ & $\begin{array}{l}221.45 \\
300.40\end{array}$ & 38.253 & 6.620 & $* *<0.0001$ \\
\hline A4 & $\begin{array}{l}\text { Laypeople } \\
\text { Dentists }\end{array}$ & $\begin{array}{l}225.22 \\
293.92\end{array}$ & 37,062 & 5.764 & $* *<0.000$ I \\
\hline
\end{tabular}

Note: **Highly statistically significant.
One of the most impressive innovations of the last few years was the introduction of digital smile design, ${ }^{11}$ a tool able to help communication between patients and dentists and to enhance predisposition of patients, and now widely used in dental practice.

According to these premises, our work showed that DSD was optioned by $68.8 \%$ of all interviewed among all other choices, reinforcing the idea that DSD is commonly appreciated. However, some clarification is a duty.

All the preview methods analyzed showed clear relationships with the demographic variables. The further analysis of standardized adjusted residuals enabled us to highlight the groups that provided greater contributions to the above relationships.

Regarding the correlation between age group and the chosen method, the main contribution was expressed by older people (more than 50 years) who chose the oral explanation, showing a better engagement of this age group by using the traditional method. This could be due to the great importance of direct doctor-patient relationship, greatly represented in higher age groups. ${ }^{19,20}$

An interesting finding was the stronger preference of females in choosing DSD, maybe due to the sense of aesthetic and the more marked attention to the details. Of course, the digital smile previsualization results in a more impressive image compared to dental wax-up. 


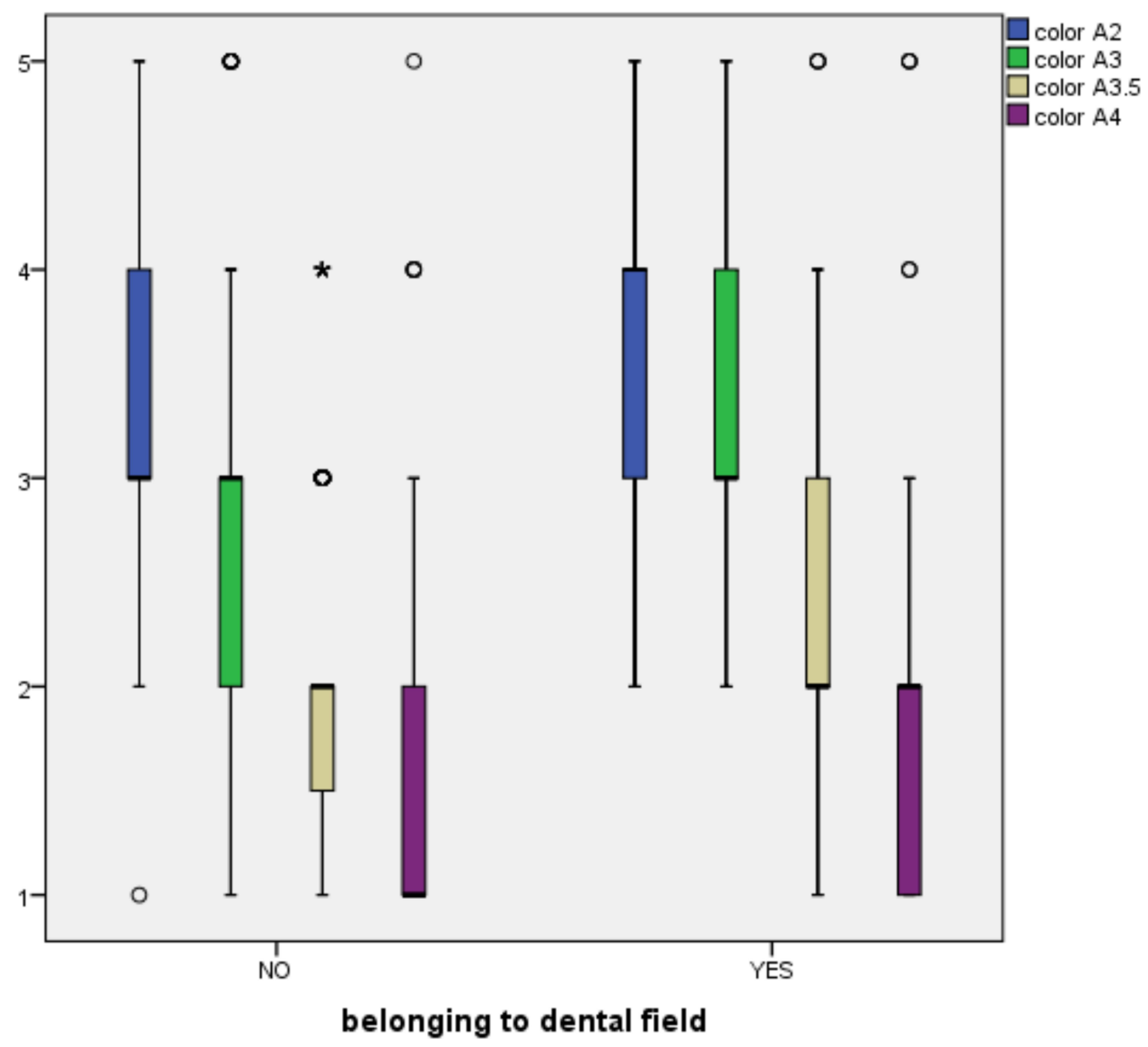

Figure 9 Graphical representation of Mann-Whitney U-test analysis about colors from A2 to A4.

It deserves to be mentioned that people with junior high school education were found to prefer oral explanation. Considering that the estimated median age of this group was 45 years old and the educational level was considered poor, it is reasonable to speculate that the group do not use new technologies. However, we must remember that the percentage of people with junior high school education is actually low in Italy and is tending to gradually disappear.

Nonetheless, these observations are of crucial importance considering the heterogeneity of the population assessed and its preference for an intuitive and immediate method of preview; this leads us to imagine that it might be really important for this technique and to spread more widely and become more accessible, both for patients and dentists and dental students.

Concerning belonging to the dental field, a significant issue is attributable to the preferences of laypeople in choosing DSD and in not expressly preferring dental waxup, whereas some dentists still decided on dental wax-up. This datum could be accountable to a certain habit of dentists in preferring a direct relationship with their dental technicians, thanks to a consolidated workflow. ${ }^{21}$ Moreover, some dentists can find in dental wax-up an easy-to-use method both to preview the result and to manage corrections more swiftly.

The low observed frequency of dentists pointing out oral explanation as favorite preview method could be probably due to their awareness about the strong correlation between the effectiveness of oral explanation and the ability of the patient to imagine the real final result combined to the availability of pictures actually related to the clinical case under examination. It is our opinion that the custom applicability of DSD preview method can effectively overcome these limitations.

In any case, these results should have to be interpreted taking into account that the laypeople group was slightly larger than the dentists' group, this could have influenced some of the data.

Recent literature showed how patients are positively influenced when the digital design is used as explanation and demonstration, such as in surgical procedures or when 


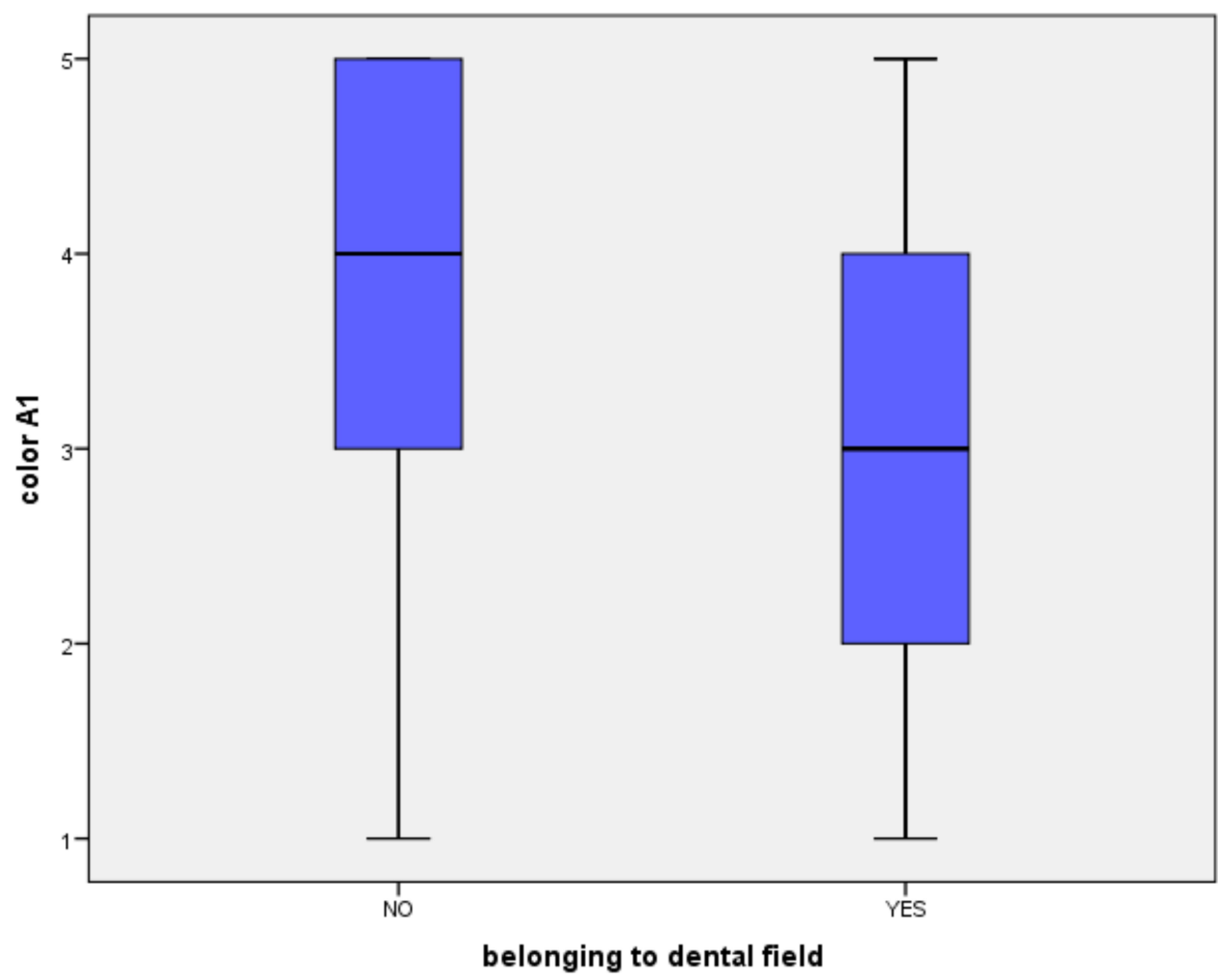

Figure 10 Graphical representation of Mann-Whitney U-test analysis about AI color.

is required a multidisciplinary approach including orthodontic, periodontal and prosthetic interventions. ${ }^{12,22-24}$

Of course, the issue of unrealistic expectations of patients deserves to be more deeply evaluated: the feasibility to have a good-looking preview of the final results could create an illusory expectation in our patients. Therefore, the right counselling, a sound and a proper explanation of the procedure and its limitation are mandatory to obtain valid consent and subsequent satisfaction of our patients. $^{25}$

Concerning the aesthetical perception of different colors, differences were highlighted between the two populations. This is not an unexpected result, literature comes to the aid in this issue showing how the aesthetic parameter is not absolute and different people have different preferences; aesthetical ideal can be influenced by ethnicity, cultural factors, individual preferences and even by trends of the moment. ${ }^{26,27}$ In dentistry also, differences were noticed between general dentists and laypeople and, no less, between general dentists and specialist ones. ${ }^{28}$

Based on this, our study aimed to evaluate these differences in aesthetical perception of most frequently used colors in restorative dentistry and to discuss the extent of this difference between the two groups. Often, dentists propose to patients aesthetic solutions that more mimic as possible rehabilitations and are able to integrate with the original features of the smile to achieve natural results. From our findings, the aesthetical rates of A2, A3, A3,5 and A4 colors were highly scored in the dentists' group compared to those of laypeople, conversely, laypeople judged the A1 colour more aesthetic than the dentists' group. This agrees with the hypothesis that dentists assess colors depending on a wide range of clinical conditions and therefore they did not express a negative rate for darker ones. Besides, general people significantly highly scored the A1 color, probably because it appeared whiter and therefore more aesthetic in their opinion. This supports the theory for which the general population label a whiter color as more aesthetic. This conclusion is supported by the literature, in a work by Samorodnitzky-Naveh et al, ${ }^{2-31}$ laypeople were found to assess their teeth darker than clinicians and they asked to have a bleaching treatment in the future.

With this in mind, the compliance and satisfaction of patients seem to be a more difficult challenge for dentists, due to plausible misunderstanding about the aesthetic concept; this could become a cause of the controversy if not well explained before performing 
complex aesthetic rehabilitations. ${ }^{32}$ Therefore, comprehensive prior information is mandatory and it might be useful to create a dedicated written informed consent for these kinds of rehabilitations when a digital method of the preview is used. Moreover, a good digital preview of final results, especially concerning colors of restored teeth, should be made; however, we are well aware that the digital rendering deviates from the natural aspect of restorations. Nevertheless, the digital preview could be good practice for dentists to make their patients more conscious about the real effect of an aesthetic result as well as to motivate them in choosing a more aesthetic and natural color for their new teeth.

All these issues are in the forefront of modern aesthetic dentistry that, now more than ever, has to deal with highperforming technologies, high-requiring patients, and great legal responsibilities.

\section{Conclusion}

We might suggest that digital dentistry is a great source for dentists and therefore it could be introduced in undergraduate programs as soon as possible to make young dentists ready to manage a challenging, smart and tricky opportunity.

\section{Disclosure}

The authors report no conflicts of interest in this work.

\section{References}

1. Garcia PP, da Costa RG, Calgaro M, et al. Digital smile design and mock-up technique for esthetic treatment planning with porcelain laminate veneers. J Conserv Dent. 2018;21(4):455-458. doi:10.4103/ JCD.JCD_172_18

2. Abduo J. Morphological symmetry of maxillary anterior teeth before and after prosthodontic planning: comparison between conventional and digital diagnostic wax-ups. Med Princ Pract. 2016;25(3):276-281. doi: $10.1159 / 000444323$

3. Jafri Z, Ahmad N, Sawai M, Sultan N, Bhardwaj A. Digital smile design-an innovative tool in aesthetic dentistry. J Oral Biol Craniofac Res. 2020;10(2):194-198. doi:10.1016/j.jobcr.2020.04.010

4. Ferrini F, Cappare P, Vinci R, Gherlone EF, Sannino G. Digital versus traditional workflow for posterior maxillary rehabilitations supported by one straight and one tilted implant: a 3-year prospective comparative study. Biomed Res Int. 2018;2018. doi:10.1155/2018/4149107

5. Ferrini F, Sannino G, Chiola C, Cappare P, Gastaldi G, Gherlone EF. Influence of Intra-Oral Scanner (I.O.S.) on the marginal accuracy of CAD/CAM single crowns. Int J Environ Res Public Health. 2019;16 (4):544. doi:10.3390/IJERPH16040544

6. Cappare P, Sannino G, Minoli M, Montemezzi P, Ferrini F. Conventional versus digital impressions for full arch screw-retained maxillary rehabilitations: a randomized clinical trial. Int J Environ Res Public Health. 2019;16(5):829. doi:10.3390/ijerph16050829

7. Gherlone E, Mandelli F, Capparè P, Pantaleo G, Traini T, Ferrini F. A 3 years retrospective study of survival for zirconia-based single crowns fabricated from intraoral digital impressions. J Dent. 2014;42 (9):1151-1155. doi:10.1016/j.jdent.2014.06.002
8. Gherlone EF, Ferrini F, Crespi R, Gastaldi G, Capparé P. Digital impressions for fabrication of definitive "all-on-four" restorations. Implant Dent. 2015;24(1):125-129. doi:10.1097/ID.0000000000000206

9. Gherlone E, Cappare P, Vinci R, Ferrini F, Gastaldi G, Crespi R. Conventional versus digital impressions for "all-on-four" restorations. Int J Oral Maxillofac Implants. 2016;31(2). doi:10.11607/ JOMI.3900

10. Cattoni F, Teté G, Calloni AM, Manazza F, Gastaldi G, Capparè P. Milled versus moulded mock-ups based on the superimposition of 3D meshes from digital oral impressions: a comparative in vitro study in the aesthetic area. BMC Oral Health. 2019;19(1):230. doi:10.1186/ s12903-019-0922-2

11. Charavet C, Bernard J-C, Gaillard C, Le Gall M. Benefits of digital smile design (DSD) in the conception of a complex orthodontic treatment plan: a case report-proof of concept. Int Orthod. 2019;17 (3):573-579. doi:10.1016/j.ortho.2019.06.019

12. Cervino G, Fiorillo L, Arzukanyan AV, Spagnuolo G, Cicciù M. Dental restorative digital workflow: digital smile design from aesthetic to function. Dent J. 2019;7(2):30. doi:10.3390/dj7020030

13. Omar D, Duarte C. The application of parameters for comprehensive smile esthetics by digital smile design programs: a review of literature. Saudi Dent J. 2018;30(1):7-12. doi:10.1016/j. sdentj.2017.09.001

14. Boparai JK, Singh S, Kathuria P. How to design and validate a questionnaire: a guide. Curr Clin Pharmacol. 2018;13 (4):210-215. doi:10.2174/1574884713666180807151328

15. Nocini R, Capocasale G, Marchioni D, Zotti F. A snapshot of knowledge about oral cancer in Italy: a 505 person survey. Int J Environ Res Public Health. 2020;17(13):13. doi:10.3390/ijerph17134889

16. Sharpe D. Chi-square test is statistically significant: now what? Pract Assess Res Eval. 2019;20(1). doi:10.7275/tbfa-x148

17. Blatz MB, Chiche G, Bahat O, Roblee R, Coachman C, Heymann HO. Evolution of aesthetic dentistry. J Dent Res. 2019;98 (12):1294-1304. doi:10.1177/0022034519875450

18. Kelleher MGD, Djemal S, Lewis N. Ethical marketing in 'aesthetic' ('esthetic') or 'cosmetic dentistry'. Part 1. Dent Update. 2012;39(5):313-316, 318-320, 323-4 passim. doi:10.12968/denu.2012.39.5.313

19. Peek STM, Wouters EJM, Luijkx KG, Vrijhoef HJM. What it takes to successfully implement technology for aging in place: focus groups with stakeholders. $J$ Med Internet Res. 2016;18(5):e98. doi:10.2196/ jmir.5253

20. Collecchia G. The doctor-patient relationship in the digital world: a Babylon?. Recenti Prog Med. 2019;110(9):397-400. doi:10.1701/ 3215.31932

21. Evans J, Henderson A, Johnson N. The future of education and training in dental technology: designing a dental curriculum that facilitates teamwork across the oral health professions. $\mathrm{Br}$ Dent $J$. 2010;208(5):227-230. doi:10.1038/sj.bdj.2010.208

22. Brucoli M, Boffano P, Pezzana A, Sedran L, Boccafoschi F, Benech A. The potentialities of the anatomage table for head and neck pathology: medical education and informed consent. Oral Maxillofac Surg. 2020;24(2):229-234. doi:10.1007/s10006-01900821-x

23. De Santis D, Malchiodi L, Cucchi A, Canton LC, Trevisiol L, Nocini PF. Computer-assisted surgery. J Craniofac Surg. 2010;21 (6):1781-1785. doi:10.1097/SCS.0b013e3181f40474

24. Lazzarotto A, Franz L, Stella E, et al. Volumetric analysis of fat injection by computerized tomography in orthognathic surgery: preliminary report on a novel volumetric analysis process for the quantification of aesthetic results. J Craniofac Surg. 2019;30(3):771-776. doi: $10.1097 /$ SCS.000000000005305

25. Johnstone P. Dento-legal implications in digital dentistry. Prim Dent J. 2018;7(2):20-23. doi:10.1177/205016841800700202

26. Tjan AH, Miller GD, The JG. Some esthetic factors in a smile. $J$ Prosthet Dent. 1984;51(1):24-28. doi:10.1016/s0022-3913(84) 80097-9 
27. Eggerstedt M, Rhee J, Urban MJ, Mangahas A, Smith RM, Revenaugh PC. Beauty is in the eye of the follower: facial aesthetics in the age of social media. Am J Otolaryngol. 2020;41(6):102643. doi:10.1016/j.amjoto.2020.102643

28. Saha MK, Khatri M, Saha SG, et al. Perception of acceptable range of smiles by specialists, general dentists and lay persons and evaluation of different aesthetic paradigms. J Clin Diagn Res. 2017;11(2): ZC25-ZC28. doi:10.7860/JCDR/2017/23359.9274

29. Samorodnitzky-Naveh GR, Grossman Y, Bachner YG, Levin L. Patients' self-perception of tooth shade in relation to professionally objective evaluation. Quintessence Int. 2010;41(5):e80-e83.
30. da Silva FMF, Magno MB, Neves AB, et al. Aesthetic perceptions and social judgments about different enamel opacities. Braz Oral Res. 2020;34:e049. doi:10.1590/1807-3107bor-2020.vol34.0049

31. Sakellaropoulos O, Lagouvardos P. Influence of lightness of teeth and lip position of a posed smile on the perception of its attractiveness. Int $J$ Esthet Dent. 2020;15(2):158-172.

32. Di Lorenzo P, Casella C, Capasso E, et al. Aesthetic dental procedures: legal and medico-legal implications. Open Med. 2018;13:96-100. doi:10.1515/med-2018-0015

\section{Publish your work in this journal}

Clinical, Cosmetic and Investigational Dentistry is an international, peer-reviewed, open access, online journal focusing on the latest clinical and experimental research in dentistry with specific emphasis on cosmetic interventions. Innovative developments in dental materials, techniques and devices that improve outcomes and patient satisfaction and preference will be highlighted. The manuscript management system is completely online and includes a very quick and fair peer-review system, which is all easy to use. Visit http://www.dovepress.com/testimonials.php to read real quotes from published authors. 